\title{
The postweaning social isolation in C57BL/6 mice preferential vulnerability in the male sex
}

\author{
Journal Article \\ Author(s): \\ Pietropaolo, Susanna; Singer, Philipp; Feldon, Joram; Yee, Benjamin K. \\ Publication date: \\ 2008 \\ Permanent link: \\ https://doi.org/10.3929/ethz-b-000009242 \\ Rights / license: \\ In Copyright - Non-Commercial Use Permitted \\ Originally published in: \\ Psychopharmacology 197(4), https://doi.org/10.1007/s00213-008-1081-3
}




\title{
The postweaning social isolation in $\mathrm{C57} \mathrm{BL} / 6$ mice: preferential vulnerability in the male sex
}

\author{
Susanna Pietropaolo • Philipp Singer • Joram Feldon • \\ Benjamin K. Yee
}

Received: 7 September 2007 / Accepted: 10 January 2008 / Published online: 4 March 2008

(C) Springer-Verlag 2008

\begin{abstract}
Introduction Social deprivation during early life can severely affect mental health later in adulthood, leading to the development of behavioural traits associated with several major psychiatric disorders including schizophrenia. This has led to the application of social isolation in laboratory animals to model the impact of environmental factors on the aetiopathology of schizophrenia. However, controversy exists over the precise behavioural profile and the robustness of some of the reported effects of social isolation rearing.

Materials and methods Here, we evaluated the efficacy of postweaning social isolation to induce schizophreniarelated behavioural deficits in C57BL/6 mice of both sexes. Results The effects of social isolation clearly differed between sexes: isolated male but not female mice exhibited multiple habituation deficits and enhanced locomotor reaction to amphetamine.

Discussion The preferential vulnerability in the male sex corresponds well with the earlier disease onset and poorer prognosis in male relative to female schizophrenic patients. In contrast, we observed no evidence for a disruption of sensorimotor gating in the prepulse inhibition paradigm despite the efficacy of social isolation to alter startle reactivity. With both success and failure in the induction of schizophrenia-related endophenotypes, the present study thus provides important characterizations and qualifications to the application of the social isolation model in mice.
\end{abstract}

S. Pietropaolo $\cdot$ P. Singer $\cdot$ J. Feldon $\cdot$ B. K. Yee $(\bowtie)$

Laboratory of Behavioural Neurobiology,

Swiss Federal Institute of Technology Zurich,

Schorenstrasse 16,

CH-8603 Schwerzenbach, Switzerland

e-mail: byee@ethz.ch
Conclusions We conclude that social isolation in mice represents a valuable tool for the examination of candidate genes within the context of the "two-hit" hypothesis of the aetiological processes in schizophrenia.

Keywords Amphetamine - Mouse - Prepulse inhibition · Open field · Anxiety $\cdot$ Schizophrenia $\cdot$ Sex differences

\section{Introduction}

The vulnerability in early life to alterations of the rearing environment, including social deprivation, is believed to play a crucial role in the aetiopathology of several major psychiatric disorders with a presumed neurodevelopmental origin (Garnefski et al. 1990; George et al. 1989). These include schizophrenia, a severe mental disorder with multiple mental dysfunctions, which is considered to result from pre- and/or postnatal disturbances of the normal course of neurodevelopment (Harrison 1997; Maynard et al. 2001).

A number of animal models have been developed based on the use of early life environmental stressors in prenatal (e.g., Fortier et al. 2004; Hauser et al. 2006; Meyer et al. 2005) or neonatal life (Ellenbroek et al. 1998; Pryce et al. 2001; Lehmann and Feldon 2000; RuediBettschen et al. 2005; Van den Buuse et al. 2003). In the social isolation paradigm, the manipulation is not implemented until weaning age (at 3 weeks of age), and it typically involves isolated housing for at least 4-6 weeks (Geyer et al. 1993; Weiss and Feldon 2001). In comparison to group-housing controls, postweaning isolation in rats (Hatch et al. 1965) and in mice (Valzelli 1973) produces a range of brain and behavioral changes (commonly referred to as the "isolation syndrome"), that may be linked to 
clinically relevant human psychopathological traits including those observed in schizophrenia (Van den Buuse et al. 2003)

The more robust effects of the isolation syndrome are: (1) increased spontaneous locomotor activity which often expresses in the form of habituation deficit (mice: Abramov et al. 2004; Benton and Brain 1981; rats: Domeney and Feldon 1998; Einon et al. 1978; Gentsch et al. 1988; Heidbreder et al. 2000), with few exceptions limited to specific strains (Geyer et al. 1993; Weiss et al. 2000, 2001a); and (2) enhancement of the sensitivity to amphetamine (mice: Wilmot et al. 1984, 1986; and rats: Jones et al. 1990; Sahakian et al. 1975; Smith et al. 1997; Weiss et al. 2001a). These findings are indicative of mesolimbic hyperdopaminergia (Dai et al. 2004; Heidbreder et al. 2000; Jones et al. 1990; Leng et al. 2004; Wilmot et al. 1986), which is closely related to the genesis of positive symptoms in schizophrenia (e.g., Gray et al. 1991; Laruelle et al. 1999).

On the other hand, some reported effects of social isolation appear to be more fragile. In particular, the finding of sensorimotor gating deficits in the paradigm of prepulse inhibition (PPI) is controversial, although it has been reported in both rats (Varty and Geyer 1998; Varty et al. 2000; Weiss et al. 2001b; Wilkinson et al. 1994) and mice (Dai et al. 2004, 2005; Sakaue et al. 2003; Varty et al. 2006). This concerns most directly the face validity of the social isolation model, as PPI deficiency is a robust (although not specific) endophenotype of schizophrenia (Turetsky et al. 2007). The controversy mainly stems from a series of findings in rats indicating that the emergence of isolation-induced PPI deficits depends on strain (Weiss et al. 2000), sex (Weiss et al. 2001b), the precise time of weaning (Cilia et al. 2005), caging conditions (Weiss et al. 1999), and prior test experience (Domeney and Feldon 1998; Weiss and Feldon 2001). Others have shown that early handling (Krebs-Thomson et al. 2001) or pretest regrouping (Varty et al. 1999) can even nullify the disruptive effect of isolation on PPI. Last but not the least, the test parameter of pulse stimulus intensity also seems critical in determining the magnitude of the PPI deficit produced by social isolation (Geyer et al. 1993).

The confusion is further compounded by the uncertainty over whether social isolation potentiates startle reaction (Dai et al. 2005; Sakaue et al. 2003; Varty and Higgins 1995; Wilkinson et al. 1994) or not (Dai et al. 2004; Varty et al. 2006) because interpretation of PPI results is often complicated by concomitant changes in startle reactivity (Swerdlow et al. 2000; Yee et al. 2005). This, in itself, is an important issue because changes in startle reactivity may stem from alterations in emotional traits related to fear and anxiety (Bradley et al. 1990; Koch and Schnitzler 1997). However, the impact of postweaning social isolation in this domain is also uncertain, with a mixture of reports documenting anxiogenic, anxiolytic and null effects after social isolation in mice (Guidotti et al. 2001; Guo et al. 2004; Moragrega et al. 2003) and rats (Lapiz et al. 2001; Maisonnette et al. 1993; Wright et al. 1991). Resolution to this uncertainty is also relevant to the model's validity given the comorbidity between schizophrenia and anxietyrelated disorders (Seedat et al. 2007).

Another critical factor is sex difference-a highly relevant demographic factor in a number of psychiatric diseases including schizophrenia (Blehar 1995; Castle et al. 1998; Hanna and Grant 1997; Seeman 1997). Male schizophrenics typically have an earlier disease onset, poorer prognosis and exhibit a more severe symptomatology (Angermeyer and Kuhn 1988; Flor-Henry 1990). PPI deficits also seem to be preferentially observed in male schizophrenic patients (Kumari et al. 2004), although the consistency of this finding has been recently questioned (Braff et al. 2005). Sex differences in response to antipsychotic medication (Raedler et al. 2006; Seedat et al. 2007), and comorbidity rate with anxiety-related disorders (Goldstein et al. 2007) have also been noted. Unfortunately, very few social isolation studies in rodents have explicitly compared subjects of both sexes. Weiss and colleagues reported that isolation disrupted PPI (Weiss et al. 2001b) and enhanced anxiety in male rats only (Weiss et al. 2004), but sensitized response to systemic amphetamine in both sexes (Weiss et al. 2001a). These authors concluded that male rats are more sensitive to the effects of social isolation (Weiss et al. 2001b). However, the sex-dependent pattern of the isolation effect differs somewhat in mice. Social isolation induced hyperactivity in male mice only (Abramov et al. 2004; Guo et al. 2004), and produced opposite effects in anxiety between males (anxiolytic, Guo et al. 2004) and females (anxiogenic, Abramov et al. 2004). On the other hand, the impact of isolation rearing on PPI has never been compared between the two sexes in mice, as all existing relevant experiments were conducted in males only (e.g., Dai et al. 2004, 2005; Sakaue et al. 2003; Varty et al. 2006).

In the present study, the behavioural effects of postweaning social isolation were evaluated in male and female C57BL/6 mice. Anxiety-like behaviours were directly assessed using the elevated plus maze (Pellow and File 1986) and the open-field test (Prut and Belzung 2003). PPI was then assessed, adopting a procedure with multiple pulse intensities that is expected to overcome possible interpretative problems arising from baseline startle reactivity differences (Yee et al. 2005). Finally, the animals' reaction to systemic amphetamine challenge was examined, providing a test for possible dopaminergic dysfunction. The present experiment employed C57BL/6 mice because as an inbred strain, they are highly suitable for studies with environmental manipulation. Furthermore, 
the $\mathrm{C} 57 \mathrm{BL} / 6$ strain is the most common genetic background for targeted molecular intervention, thus its use would maximize the relevance of the present study to the application of the social isolation model to investigate the gene-environment interactions involved in the aethiopathology of schizophrenia.

\section{Materials and methods}

\section{Subjects and housing conditions}

Male and female C57BL6/J mice were bred in the SPF (specific-pathogen-free) facility in the Laboratory of Behavioural Neurobiology (ETH, Zurich). The present study used a total of 51 subjects derived from six independent litters. Only litters with at least four animals belonging to each sex were selected. Members within each litter were randomly subdivided into two housing conditions with an equivalent contribution of each sex. We further ensured that each cage of the grouped condition comprised mice originating from at least two distinct litters. This procedure not only minimized possible confounding due to litter effects (Zorrilla 1997), but also balanced the contribution of the litters to each housing condition. Here, we refrained from assessing the females' cycle status to avoid stress associated with repeated vaginal smear samplings required for an accurate documentation of individual animals' oestrous cycle. Furthermore, this would have introduced a confounding factor with sex because the vaginal smear sampling cannot be performed in male mice. Such confound would have negatively affected our ability to interpret any observed sex differences.

We adopted the convention to initiate the isolation housing condition at the early postweaning (juvenile) phase because it constitutes the critical period for the effects of social isolation in rats (Einon et al. 1978, 1981; Einon and Morgan 1977, 1978) and in mice (Dyer and Southwick 1974; Terranova et al. 1993). This period is also highly sensitive to other forms of environmental manipulation (Pietropaolo et al. 2004, 2006, 2007, 2008). The animals were weaned on postnatal day 1 and transferred to a separate temperature and humidity-controlled $\left(22^{\circ} \mathrm{C}, 55 \%\right)$ animal room to begin the two experimental housing conditions: (1) isolated, in which mice were individually housed in Makrolon transparent cages of $41 \times 20 \times 19 \mathrm{~cm}$, (2) grouped, in which mice were housed in unisexual groups of four to five in Makrolon cages, measuring $61 \times$ $33 \times 18 \mathrm{~cm}$. All cages (Tecniplast, Milan, Italy) were provided with weekly renewed sawdust bedding (Schill AG, Muttenz, Switzerland) and a stainless steel wired lid. Food chow (Provimi Kliba SA, Kaiseraugst, Switzerland) and water bottles were provided on the top of each cage ad libitum. The grouped condition included 13 females and 15 males, while the isolated group consisted of 12 females and 11 males. The animals were maintained under a 12:12 h reversed light-dark cycle (light off 0800-2000 hours).

Behavioural testing commenced 4 weeks from the beginning of isolation housing, which is in keeping with previous mouse studies (Dai et al. 2004, 2005; Varty et al. 2006). Over a period of approximately 2 weeks, the mice were subjected to tests of anxiety, locomotor activity, prepulse inhibition of the acoustic startle response and amphetamine-induced hyperactivity (as described below in chronological order). A test-free period of at least 2 days was always allowed between successive tests. All tests were conducted in the dark phase. Similar to previous isolation studies (Bakshi and Geyer 1999; Einon and Morgan 1978; Varty et al. 2006; see also Renner and Rosenzweig 1987), the animals were maintained in the corresponding housing conditions throughout the experimental period.

All manipulations described had been approved by the Cantonal Veterinary Authority of Zurich and were in accordance to the Principles of Laboratory Animal Care (NIH publication No. 86-23, revised 1985).

\section{Behavioural procedures}

\section{Elevated plus maze}

Apparatus The elevated plus maze was made of clear acrylglass made opaque by black self-adhesive foil ("d-cfix", Konrad Hornschuch, Weissbach, Germany) with a removable plastic grey floor. It was elevated $70 \mathrm{~cm}$ above floor level and positioned in the middle of a testing room with diffuse dim lighting ( $25 \mathrm{~lx}$ in the centre). It consisted of four equally spaced arms radiating from a central square measuring $5 \times 5 \mathrm{~cm}$. Each arm was $30 \mathrm{~cm}$ long and $5 \mathrm{~cm}$ wide. One pair of opposing arms was enclosed with opaque walls, $14 \mathrm{~cm}$ high, except for the side adjoining the central square. The remaining two arms were exposed with a 3mm-high parameter border along the outer edges. A digital camera was mounted above the maze. Images were captured at a rate of $5 \mathrm{~Hz}$ and transmitted to a PC running the Ethovision (Version 3.1, Noldus Technology, the Netherlands) tracking system.

Procedures To begin a trial, the mouse was gently placed in the central square with its head facing one of the open arms. It was allowed to explore freely and undisturbed for $5 \mathrm{~min}$. Two anxiety-related measures were calculated: percent time in open arms $=$ time in open arms/time in all arms $\times 100 \%$, and percent entries into open arms $=$ entries into open arms/ entries into open or enclosed arms $\times 100 \%$. 


\section{Open-field test}

Apparatus The apparatus consisted of four identical square arenas, each measured $40 \times 40 \mathrm{~cm}$ in surface area and was surrounded on all sides by a $25-\mathrm{cm}$ wall. The open field was made of wood with a white waterproof plastic surface. They were located in a testing room under diffused dim lighting (30 lx). A digital camera was mounted directly above the four arenas, capturing images from all four arenas at a rate of $5 \mathrm{~Hz}$. The images were transmitted to a PC running the Ethovision tracking system (Version 3.1, Noldus Technology, The Netherlands).

Procedures The mice were tested in squads of four. They were gently placed in the centre of the appropriate arena and allowed to explore undisturbed for $1 \mathrm{~h}$. Afterwards, they were returned to the home cage and the arenas cleansed with water and dried before the next squad. Locomotor activity was indexed by distance travelled recorded in successive 10-min bins. In addition, the exploration of a central region $(13 \times 13 \mathrm{~cm})$ of the openfield arena was also recorded; this anxiety-related measure may be considered as an index of phobia towards open spaces (Prut and Belzung 2003).

\section{Prepulse inhibition of the acoustic startle reflex}

Apparatus The apparatus consisted of four acoustic startle chambers for mice (SR-LAB, San Diego Instruments, San Diego, CA, USA) each comprised a nonrestrictive cylindrical enclosure made of clear Plexiglas attached horizontally on a mobile platform, which was, in turn, resting on a solid base inside a sound-attenuated isolation cubicle. A high-frequency loudspeaker mounted directly above the animal enclosure inside each cubicle produced a continuous background noise of $65 \mathrm{~dB}_{\mathrm{A}}$ and the various acoustic stimuli in the form of white noise. Vibrations of the Plexiglas enclosure caused by the whole-body startle response of the animal were converted into analogue signals by a piezoelectric unit attached to the platform. These signals were digitized and stored by a computer. A total of 130 readings was taken at $0.5-\mathrm{ms}$ intervals (i.e., spanning across $65 \mathrm{~ms}$ ), starting at the onset of the startle stimulus in pulse-alone and prepulse-plus-pulse trials, and at the onset of the prepulse stimulus in prepulse-alone trials. The average amplitude over the $65 \mathrm{~ms}$ was used to determine the stimulus reactivity. The sensitivity of the stabilimeter was routinely calibrated to ensure consistency between chambers and across sessions.

Procedures Here, we adopted the procedures and testing parameters used for the evaluation of PPI in mice of the same strain by Yee et al. (2005). Briefly, PPI was assessed in a test session lasting for approximately $40 \mathrm{~min}$, in which the subjects were presented with a series of discrete trials comprising a mixture of four types of trials. These included pulse-alone trials, prepulse-plus-pulse trials, prepulse-alone trials and trials in which no discrete stimulus, other than the constant background noise, was presented. A reduction of startle magnitude in prepulse-plus-pulse trials relative to that in pulse-alone trials constitutes PPI.

Pulse stimuli of three different intensities were employed: 100,110 and $120 \mathrm{~dB}_{\mathrm{A}}$. These were of $40 \mathrm{~ms}$ in duration. Prepulses of three intensities were employed: 71 , 77 and $83 \mathrm{~dB}_{\mathrm{A}}$, which corresponded to 6,12 , and $18 \mathrm{~dB}$ units above background, respectively. The duration of prepulse stimuli was $20 \mathrm{~ms}$. The stimulus onset asynchrony (SOA) of the prepulse and pulse stimuli on prepulse-pluspulse trials was $100 \mathrm{~ms}$.

A session began when animals were placed into the Plexiglas enclosure. They were acclimatised to the apparatus for 2 min before the first trial began. The first six trials consisted of six pulse-alone trials: two trials of each of the three possible pulse intensities. These trials served to habituate and stabilize the animals' startle response and were analysed separately. Subsequently, the animals were presented with ten blocks of discrete test trials. Each block consisted of the following: three pulse-alone trials $\left(100,110\right.$ or $\left.120 \mathrm{~dB}_{\mathrm{A}}\right)$, three prepulse-alone trials $(+6,+12$, or $+18 \mathrm{~dB}$ units above background), and nine possible combinations of prepulse-plus-pulse trials ( 3 levels of prepulse $\times 3$ levels of prepulse), and one no-stimulus (i.e., background alone). The 16 discrete trials within each block were presented in a pseudorandom order, with a variable intertrial interval of a mean of $15 \mathrm{~s}$ (ranging from 10 to $20 \mathrm{~s}$ ). The session was concluded with a final block of six consecutive pulsealone trials as in the first block.

\section{Amphetamine-induced hyperactivity}

Procedures D-Amphetamine sulfate, obtained from SigmaAldrich (Switzerland), was dissolved in $0.9 \% \mathrm{NaCl}$ solution to obtain the desired dosage $(2.5 \mathrm{mg} / \mathrm{kg}$, calculated as the salt). The substance was freshly prepared on the required days in solution form and was administered via the intraperitoneal (i.p.) route.

Mice were given a 30-min session of free exploration of the open-field test (baseline exploration) as previously described. They were then briefly removed from the open field and injected with either $0.9 \% \mathrm{NaCl}$ or amphetamine solution before being returned to the open field for $90 \mathrm{~min}$. The allocation of drug conditions was balanced across all between-subject factors, and with respect to their locomotor activity levels in the previous open-field test. 
Data analysis The distance moved was measured in 10-min bins for both the pre- and postinjection sessions. Furthermore, an activity ratio was derived as follows: distance moved during each 10-min bin of the postinjection session/ distance moved during the last 10-min bin of the preinjection session. This provides a more sensitive index of the drug's locomotor-enhancing effect, taking into account individual variation before injection.

\section{Statistical analysis}

All data were analysed by parametric analysis of variance (ANOVA) using housing condition and sex as the betweensubjects factors. Additional within-subject factors (e.g., 10min bins) were also included according to the nature of the considered dependent variables. Post hoc comparisons were performed using Fisher's PLSD test based on the overall error variance associated with the relevant factor. Supplementary restricted analyses were also conducted to assist data interpretation whenever appropriate. To better conform to the normality and variance homogeneity assumptions of parametric ANOVA, logarithmic transformation (base e) was applied to the startle reactivity scores in the prepulse inhibition experiment, except in the habituation analysis when this was not necessary. Likewise, a square-root transformation was applied to the activity ratio measure in the amphetamine locomotor experiment. All statistical analyses were carried out using SPSS for Windows (release 13, SPSS Inc. Chicago IL, USA) implemented on a PC running the Windows XP (SP2) operating system.

\section{Results}

Elevated plus maze

Social isolation did not affect anxiety-like behaviour regardless of sex. The mean values $( \pm \mathrm{SEM})$ of the percent time spent in the open arms were: grouped males $=20.12 \pm$ $5.05 \%$; isolated males $=13.55 \pm 3.54 \%$; grouped females $=$ $6.86 \pm 1.88 \%$; isolated females $=14.92 \pm 4.84 \%$.

A $2 \times 2$ (sex $\times$ housing condition) ANOVA of the percent time spent in the open arms revealed no significant effect. However, female mice tended to display higher anxiety levels compared to males, but this effect was mainly observed in group-housed controls. Although the interaction sex $\times$ housing condition failed to reach statistical significance $[F(1,47)=3.05, p=0.09]$, restricted analyses revealed a significant sex difference in grouped animals only $(p<0.05)$. Analysis of the alternative measure of percent entries into the open arms yielded a highly similar pattern of results.
Open-field test

First, social isolation did not affect anxiety-like behaviour in the open field. An ANOVA of percent time spent in the central area revealed no significant difference between housing conditions, or between sexes. The mean values $( \pm \mathrm{SEM})$ were: grouped males $=8.69 \pm 1.68 \%$; isolated males $=7.99 \pm 1.83 \%$; grouped females $=6.53 \pm 0.81 \%$; isolated females $=8.21 \pm 1.26 \%$. Additional analyses of the other anxiety measures (number of entries into the central zone and percent distance moved in the central zone) yielded a similar pattern of results.

Second, locomotor activity as measured by distance travelled per 10-min bin decreased over time, indicating locomotor habituation. Habituation was present in all groups, but the rate of habituation appeared to be slower in isolated male mice relative to the male grouped controls (Fig. 1). These impressions were supported by a $2 \times 2 \times 6$ (sex $\times$ housing condition $\times 10$-min bins) split-plot ANOVA, which revealed a significant main effect of bins $[F(5,235)=$ 149.73, $p<0.0001$ ], and a significant interaction between housing condition and bins $[F(5,235)=3.16, p<0.05]$. Although the housing by sex interaction failed to attain statistical significance $[F(1,47)=2.75, p=0.10]$, separate analyses confirmed that a significant housing condition $\times$ bins interaction was apparent in male $[F(5,120)=2.65$, $p<0.05]$, but absent in female animals $[F(5,115)=1.08$,
MALES

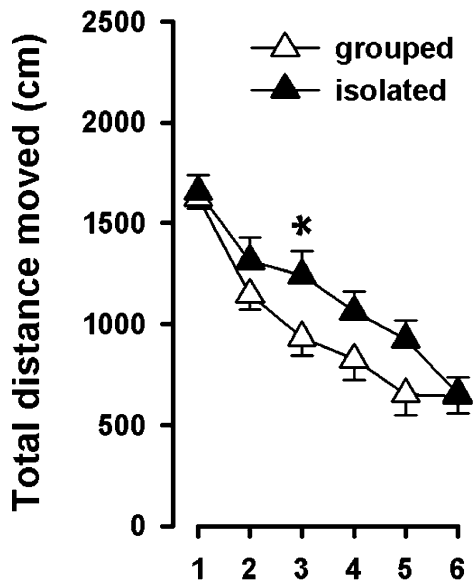

10-min bins
FEMALES

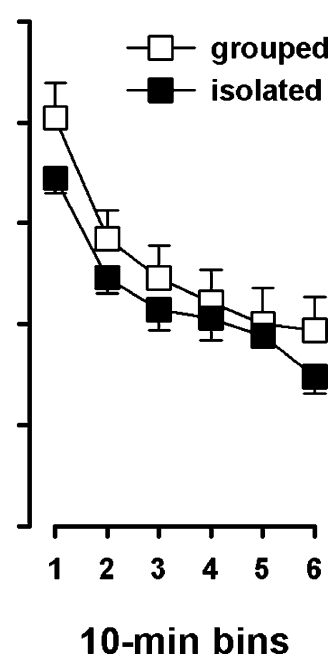

Fig. 1 Locomotor activity in the open-field test. Locomotor habituation expressed as the time-dependent decrease in distance travelled, was observed in all experimental groups, but was attenuated by social isolation. This effect was selectively observed in male mice. Data are means \pm SEM. ${ }^{*} p<0.05$, based on the pooled error variance associated with the significant housing condition $\times$ bins interaction in the ANOVA restricted to male subjects. The grouped condition included 13 females and 15 males, while the isolated group comprised 12 females and 11 males 
$p=0.38]$. Post hoc pair-wise comparisons at successive bins confirmed that the isolated males showed significantly higher levels of locomotor activity compared to grouped controls in the third 10-min bin of the test.

Prepulse inhibition of the acoustic startle reflex

Startle habituation Startle habituation was evaluated by a comparison of mean startle reaction obtained in the first and the last blocks of six consecutive pulse-alone trials (two of each pulse intensity). As illustrated in Fig. 2, a reduction of reactivity in the last relative to the first block was apparent in all groups except the male isolated animals. These animals showed instead a sensitization effect with reactivity in the last block being higher than in the first. In contrast, isolation did not affect the startle habituation in the female, but substantially reduced overall startle reactivity. There were thus two sex-specific isolation effects here: in each case, the isolation effect was accentuated by increasing pulse intensity, as both effects are most readily discerned at the highest pulse intensity of $120 \mathrm{~dB}_{\mathrm{A}}$.

A $2 \times 2 \times 2 \times 3$ (housing condition $\times$ sex $\times$ blocks $\times$ pulse intensity) ANOVA revealed a number of significant effects. There was no overall significant effect of blocks, but the factor blocks showed significant interaction separately with $\operatorname{sex}[F(1,47)=6.69, p<0.05]$ and with housing condition $[F$ $(1,47)=5.62, p<0.05]$. The presence of these significant interactions stemmed mainly from the unique presence of a sensitization (instead of habituation) profile in the isolated male. The housing condition $\times$ sex $\times$ blocks interaction, however, failed to attain statistical significance $[F(1,47)=$
3.26, $p=0.08$ ], and was likely to be due to a lack of statistical power.

As expected, the effect of pulse intensity was highly significant $[F(2,94)=74.48, p<0.001]$. Pulse intensity did not interact separately with sex, housing condition, or blocks [all $F_{\mathbf{S}}<1$ ]. Instead, the housing condition $\times \operatorname{sex} \times$ pulse intensity interaction attained statistical significance $[F(2,94)=4.50, p<0.05]$. This three-way interaction should be interpreted in conjunction with the significant housing condition $\times$ sex interaction $[F(1,47)=8.42, p<$ $0.01]$ because of the female-specific, startle-attenuating effect of isolation that was most clearly seen at higher pulse intensity.

To further examine the two sex-specific effects, separate analyses were conducted restricted to either sex. Consistent with the interpretations above, a housing condition $\times$ blocks interaction was present in the male $[F(1,24)=8.88, p<0.01]$, but not in the female $[F<1]$. In the male, when the first and last block was separately analysed, a clear effect of isolation emerged only in the last block $[F(1,24)=6.40, p<0.05]$ but not in the first block $[F<1]$. These statistical outcomes supported the impression that social isolation exerted an impact on startle habituation selectively in the male. On the other hand, the equivalent analyses in the females revealed an effect of housing condition separately at each block [first block: $F(1,23)=5.30, p<0.05$, and last block: $F(1,23)=$ $7.45, p<0.05]$. This impression was reinforced by the presence of a significant housing condition effect in the analysis restricted to the female animals $[F(1,23)=7.42$, $p<0.05]$.
MALE-GROUPED

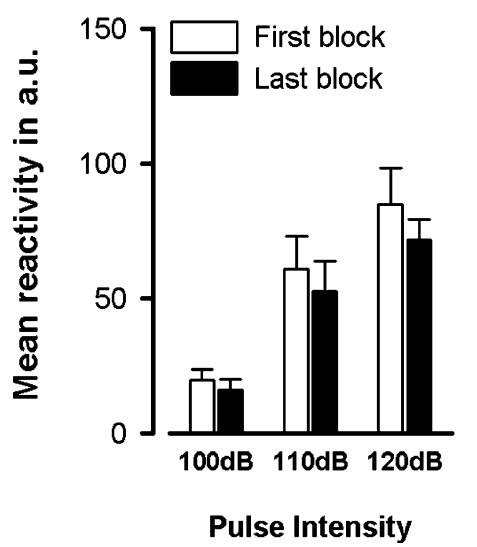

Fig. 2 Startle habituation. Startle habituation was analysed by comparing the first vs. the last two-trial blocks of each pulse intensity. Mice of all groups habituated in their acoustic startle response, with the exception of isolated males, showing the opposite tendency. Social isolation significantly reduced startle reactivity in females, and this effect was consistently observed across the different pulse levels,
FEMALE-GROUPED FEMALE-ISOLATED
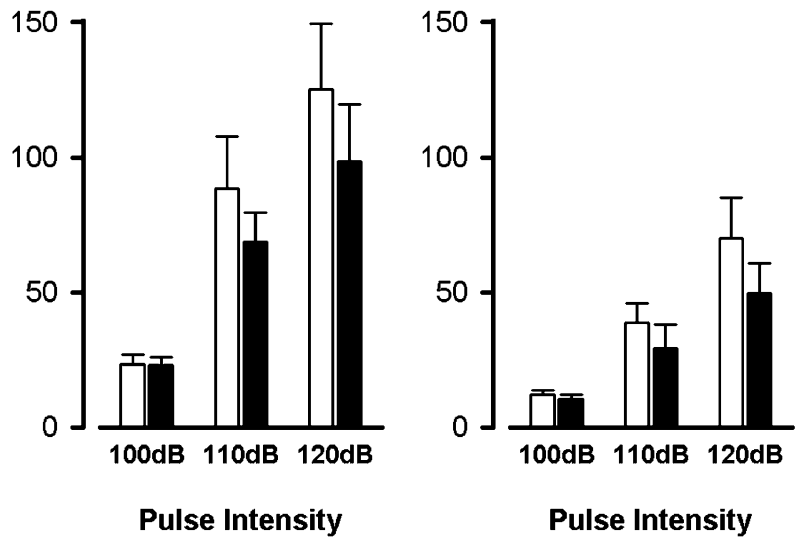

blocks and trials. These conclusions were supported by the housing condition $\times$ blocks interaction which was present only in the male $(p<$ $0.01)$, while a significant housing condition effect was observed in the female $(p<0.05)$. Data are means \pm SEM expressed in arbitrary units (a.u.) 
Pulse reactivity Next, we examined the animals' startle reaction obtained in the intermediate block of pulse-alone trials that were presented intermixed with other types of trials (i.e., in-between the first and last blocks of pulsealone trials described above). This further consolidated the presence of opposing sex-specific effects of social isolation on startle reactivity. In summary, social isolation attenuated startle reactivity in females, but potentiated startle response in males. These effects were observed against little or no difference between the sexes in the grouped housing condition. The mean (in arbitrary units followed by $\ln$ transformed \pm SEM) reactivity score in four groups was: male grouped $=3.57 \pm 0.09$, male isolated $=3.88 \pm 0.11$, female grouped $=3.68 \pm 0.10$, female isolated $=3.31 \pm 0.10$ (also see Fig. 3).

These conclusions were supported by a $2 \times 2 \times 3$ (housing condition $\times$ sex $\times$ pulse intensity) ANOVA of (ln transformed) mean startle reactivity in the intermediate block, which yielded a significant housing condition $\times$ sex interaction $[F(1,47)=11.54, p=0.001]$ and an overall main effect of sex $[F(1,47)=5.23, p<0.05]$. The main effect of pulse intensity also achieved significance as expected $[F(2,94)=224.48, p<0.001]$. The sex effect and its interaction effect were largely independent of pulse intensity: the three-way interaction did not attain statistical significance $[F<1]$. Post hoc pair-wise comparisons amongst the four groups revealed a significant housing difference in the male $[p<0.05]$ and in the female $[p<$ $0.05]$. There was no difference between sexes in the grouped housing condition $[p=0.41]$, but a highly significant sex difference was observed in the isolated housing condition $[p=0.0003]$.
Prepulse inhibition of the acoustic startle response A reduction of startle reactivity to the pulse stimulus on prepulse-plus-pulse trials relative to pulse-alone trials constitutes the prepulse inhibition (PPI) effect. We focused first on an analysis of the mean reactivity score obtained on both pulse-alone and prepulse-plus-pulse trials instead of using percent inhibition as the measure of PPI because of the clear presence of an isolation effect on startle reactivity (see above) and that the direction of the effect depended further on sex. This approach is recommended when there are confounding changes in startle reactivity on pulse-alone trials (Swerdlow et al. 2000; Yee et al. 2005). As illustrated in Fig. 3, startle reactivity fell with increasing prepulse stimulus intensity (with prepulse intensity of " +0 " referring to pulse-alone condition), constituting the PPI effect. The magnitude of this reduction and its dependency on prepulse intensity was largely unaffected by social isolation.

A $2 \times 2 \times 3 \times 4$ (housing condition $\times$ sex $\times$ pulse intensity $\times$ prepulse intensity) ANOVA of 1 -transformed reactivity scores revealed a main effect of pulse $[F(2,94)=179.76$, $p<0.0001]$, of prepulse intensity $[F(3,141)=270.21$, $p<0.0001]$, and their interaction $[F(6,282)=10.84$, $p<0.0001]$. These effects indicated the overall impact of pulse intensity on reactivity, the expression of an overall PPI effect and the dependency of PPI on pulse intensity, respectively (see Fig. 3). Consistent with the analysis on pulse reactivity above, isolation generally enhanced reactivity in male mice but attenuated it in females. Here, these opposing effects gave rise to a significant effect of sex $[F(1,47)=6.42, p<0.05]$ and of its interaction with housing condition $[F(1,47)=9.30, p<0.05]$.
Fig. 3 Prepulse inhibition of the acoustic startle. The analysis of the mean reactivity scores showed that social isolation exerted opposite effects in male and female mice, and they were mainly evident at the highest levels of pulse intensities. When the data were further examined by matching the pulse-alone reactivity amongst experimental groups (see arrows), no effect of social isolation was found. Data are means \pm SEM. The measures of mean reactivity were subjected to a natural logarithmic transformation before analysis to better conform to the assumptions of parametric ANOVA.

The grouped condition included 13 females and 15 males, while the isolated group comprised 12 females and 11 males
MALE

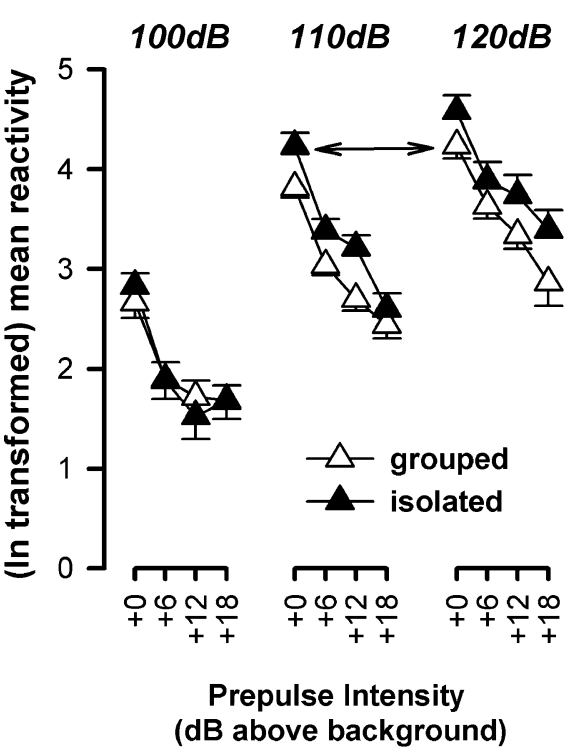

FEMALE

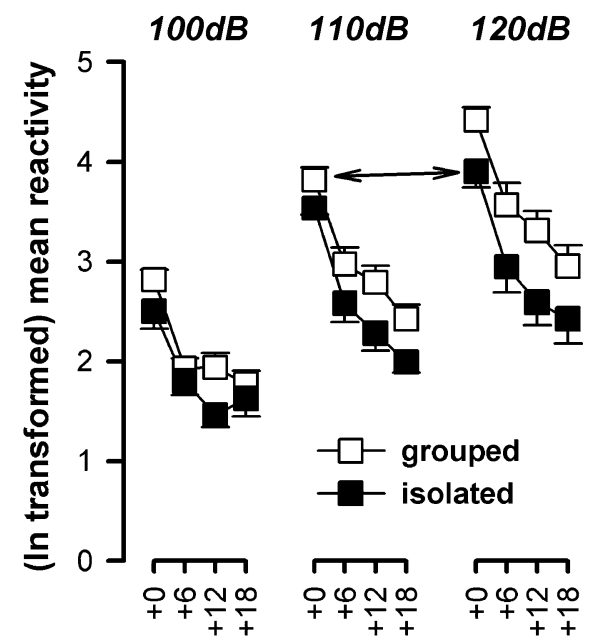

Prepulse Intensity (dB above background) 
To circumvent the confounding effect of isolation on startle reactivity per se (pulse-alone, i.e., at " +0 " condition of Fig. 3), we reexamined the isolation effect in each sex by matching the mean reactivity scores on pulse-alone trials between isolated and grouped housing conditions as indicated by the double-headed arrows in Fig. 3. Thus, isolated males' performance at $110 \mathrm{~dB}_{\mathrm{A}}$ pulse condition was compared with grouped males' at $120 \mathrm{~dB}_{\mathrm{A}}$ pulse condition; and isolated females' performance at $120 \mathrm{~dB}_{\mathrm{A}}$ pulse condition were contrasted with grouped females at $110 \mathrm{~dB}_{\mathrm{A}}$ pulse condition. None of these comparisons yielded any statistical suggestion of a difference between the two housing conditions or a housing condition $x$ prepulse intensity interaction [all $\left.F_{\mathbf{S}}<1\right]$.

As illustrated by Table 1, the same conclusion of a lack of PPI deficit after social isolation was obtained by the analysis of the percent PPI, [\%PPI at prepulse $[x]$ with pulse $[y]=100 \%-($ mean reaction on prepulse $[x]$-plus-pulse $[y]$ trials $) /($ mean reaction on pulse $[y]$-alone trials $)]$. The $2 \times$ $2 \times 3 \times 3$ (housing condition $\times \operatorname{sex} \times$ pulse intensity $\times$ prepulse intensity) ANOVA of the percent PPI revealed no significant effect of housing conditions, sex or their interaction [all $F_{\mathbf{S}}<1$ ]. Although a significant interaction housing condition $\times$ pulse intensity $\times$ prepulse intensity $[F$ $(4,188)=2.47, p<0.05]$ was found, this effect was due to a PPI enhancement (potentially exaggerated by the percentage expression) observed in isolated mice only at the lowest pulse intensity. When the pulse intensity of $100 \mathrm{~dB}_{\mathrm{A}}$ was excluded from the analysis, the ANOVA confirmed a nonsignificant interaction housing condition $\times$ prepulse intensity $[F(2,94)=2.08, p=0.13]$.
A null effect of isolation on PPI was also obtained by performing a matching analysis on the percent PPI, as previously described for the mean reactivity scores, lending support to the conclusion that the expression of PPI was statistically indistinguishable between the two housing conditions when reactivity on pulse-alone condition was closely matched (Table 1).

Reaction to the prepulse stimulus alone

Analysis of the animals' direct reaction to the prepulse stimulus and in comparison to control "no-stimulus" trials revealed that a monotonic increase in reactivity, that was largely independent of housing conditions or sex. The mean reactivity (ln-transformed) at each of the four levels of prepulse intensity was: background (no stimulus) $=1.49 \pm$ $0.09,+6 \mathrm{~dB}=1.43 \pm 0.10,+12 \mathrm{~dB}=1.56 \pm 0.09,+18 \mathrm{~dB}=$ $1.73 \pm 0.08$. A $2 \times 2 \times 4$ (housing condition $\times$ sex $\times$ prepulse intensity) ANOVA of the ln-transformed reactivity scores obtained on these trials yielded a main effect of prepulse $[F$ $(3,141)=7.11, p<0.05]$. There were no other significant effects.

\section{Amphetamine-induced hyperactivity}

Baseline exploration of the open field did not differ among groups. Locomotor habituation, indexed by the timedependent decrease in locomotor activity, was equally observed in all animals during the 30-min session of baseline exploration the open-field test. These conclusions were supported by a $2 \times 2 \times 3$ (housing condition $\times \operatorname{sex} \times 10$ -

Table 1 Quantification of the prepulse inhibition (PPI) effect in terms of percent inhibition

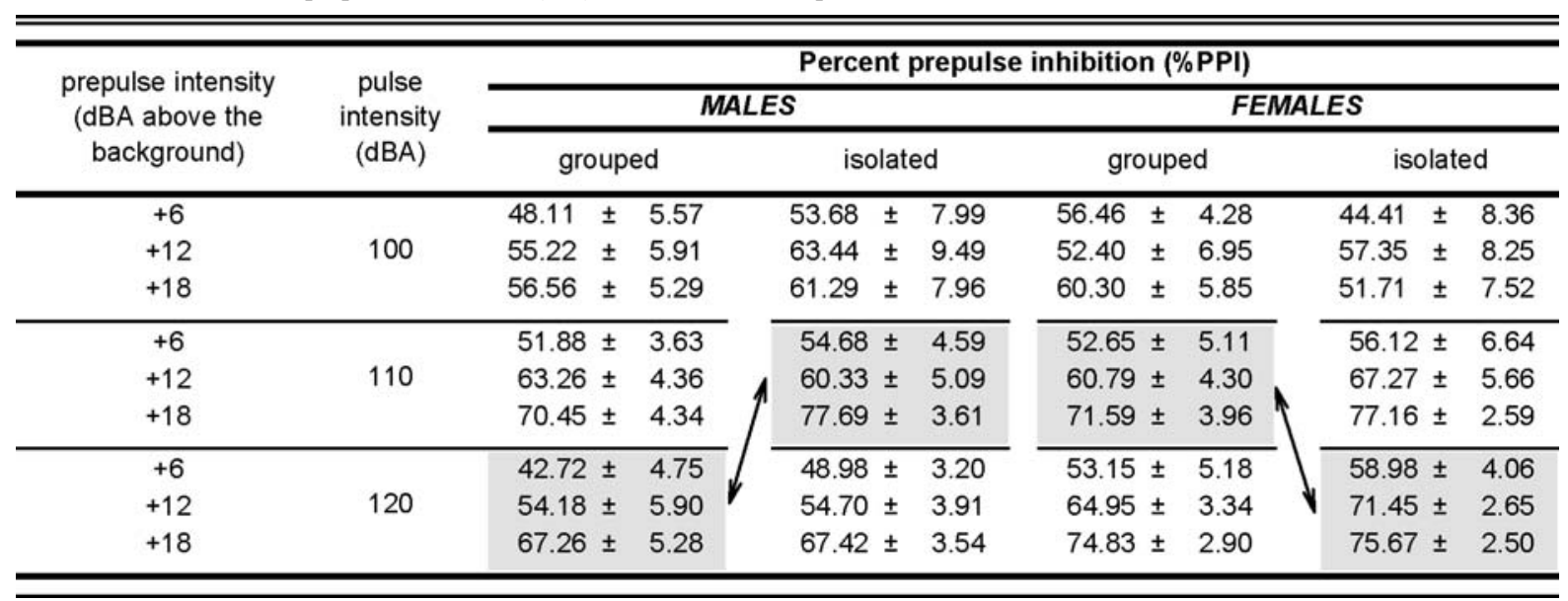

The assessment of PPI was performed employing multiple pulse intensities, to overcome the interpretative problems arising from baseline startle reactivity differences (Yee et al. 2005). This procedure allowed us to analyze the percent PPI $[\%$ PPI at prepulse $[x]$ and pulse $[y]=100 \%-($ mean reaction on prepulse $[x]$-plus-pulse $[y]$ trials)/(mean reaction on pulse $[y]$-alone trials)] by matching the pulse-alone reactivity amongst experimental groups (see arrows). These comparisons demonstrated no significant difference among the experimental groups. The grouped condition included 13 females and 15 males, while the isolated group consisted of 12 females and 11 males. Data are means \pm SEM. 
min bins) ANOVA of the distance moved, yielding a significant main effect of 10 -min bins $[F(2,94)=228.93$, $p<0.0001]$, with no other effect attaining statistical significance. The mean ( \pm SEM, in $\mathrm{m})$ distance travelled in the last $10 \mathrm{~min}$ of the baseline phase were as follows: male isolated $=12.02 \pm 2.48$, male grouped $=17.65 \pm 2.16$, female isolated $=16.60 \pm 3.39$, female grouped $=14.89 \pm 2.61$.

In the drug phase of the experiment, amphetamine treatment elevated locomotor activity in all groups relative to saline injection, with a peak response at bins 3-4. Social isolation appeared to potentiate the animals' response to amphetamine, but this effect was only seen in the male sex (Fig. 4).

A $2 \times 2 \times 2 \times 9(\operatorname{sex} \times$ housing condition $\times$ drug $\times 10$-min bins) ANOVA of the activity ratio yielded a main effect of drug $[F(1,43)=19.12, p<0.0001]$, bins $[F(8,344)=10.68$, $p<0.0001]$, and their interaction $[F(8,344)=10.17$, $p<0.0001]$. These confirmed the efficacy of amphetamine to increase activity and its time-dependent profile, respectively. The unique effect of isolation in the male mice also gave rise to the significant higher-order interactions of housing condition $\times$ drug $\times$ bins $[F(8,344)=2.67, p<0.05]$, and of sex $\times$ drug $\times$ bins $[F(8,344)=2.26, p<0.05]$. These interaction terms indicated separately that the impact of social isolation on amphetamine-induced locomotor activity depended on housing conditions and differed between sexes. The critical four-way interaction, however, only approached statistical significance $[F(8,344)=1.88, p=$ $0.06]$. We therefore sought further statistical evidence with separate analyses restricted to either sex. These revealed a significant housing condition $\times$ drug $\times$ bins interaction only in the male $[F(8,176)=3.45, p<0.05]$ but not in females $[F<1]$, thereby lending support to the conclusion that social isolation preferentially exacerbated the reaction to amphetamine in the male sex.

\section{Discussion}

The present study further characterised the impact of postweaning social isolation in C57BL/6 male and female mice and provided an assessment of its face validity as a model of schizophrenia. Here, we showed that social isolation enhanced locomotor activity, attenuated locomotor habituation, reversed the startle habituation effect, and potentiated the locomotor response to systemic amphetamine. All these effects were preferentially observed in the male sex. However, isolation was not entirely behaviourally ineffective in the female mice, as it significantly attenuated their startle reactivity. Interestingly, social isolation exerted an opposite effect on startle reactivity in the male. Neither of these effects can be readily attributed to an anxiolytic or axiogenic trait because isolation apparently did not affect anxiety-related behaviour, as demonstrated in the elevated plus maze and open-field test. Sensorimotor gating in the form of PPI was also unaffected by social isolation, even though isolated male mice displayed a sensitized response to amphetamine.
MALE-GROUPED

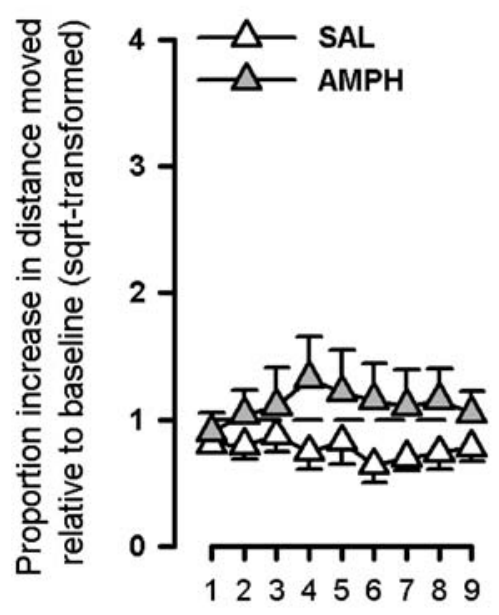

10-min bins
MALE-ISOLATED

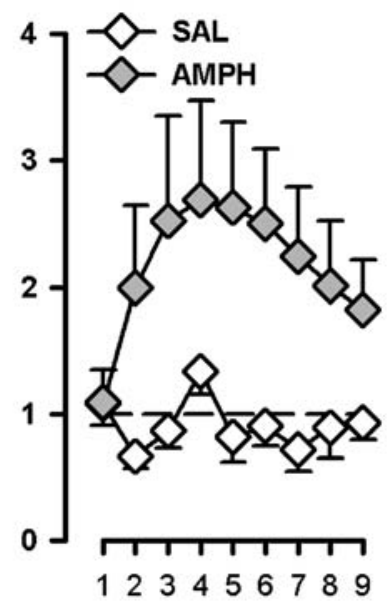

10-min bins

Fig. 4 Amphetamine-induced hyperactivity. Social isolation enhanced the locomotor response to amphetamine in the 90-min session of the open-field test, and this effect was more pronounced in males than in females. A significant housing condition $\times$ drug $\times$ bins interaction $(p<0.05)$ was obtained in the ANOVA restricted to male

FEMALE-GROUPED

FEMALE-ISOLATED

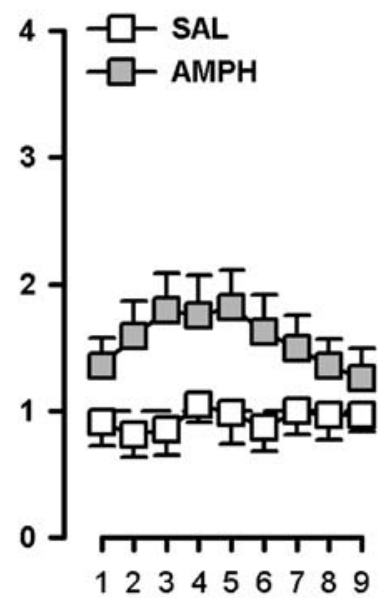

10-min bins

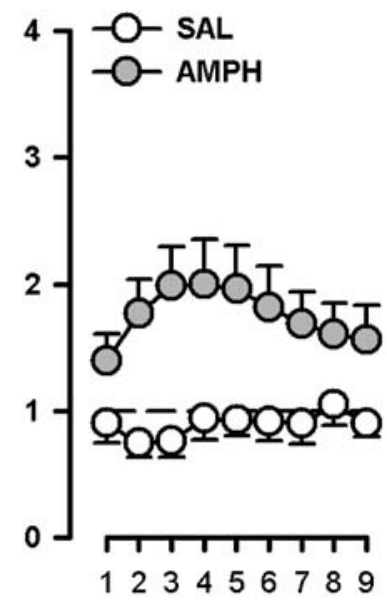

10-min bins subjects. The number of subjects in each group was: male grouped, seven SAL and eight AMPH; male isolated, six Sal and five Amph; female grouped, six SAL and seven AMPH; female isolated, six SAL and six AMPH. Dotted line represents baseline locomotor activity. Data are means \pm SEM 
Sex dependency of the social isolation effect

Our data therefore indicate that male C57BL/6 mice are consistently (across paradigms) more sensitive than females to the impact of early life social isolation. A similar malepreferential profile has been previously shown in another mouse strain (Guo et al. 2004) and suggested on the basis of data in rats (Weiss et al. 2001b). Hence, there is converging evidence to conclude that this sex difference is a robust feature of social isolation effects. This may be considered an advantage for an animal model of schizophrenia that adds to its validity because male schizophrenics typically exhibit a more severe clinical profile and an earlier onset of the disease than female patients (Angermeyer and Kuhn 1988; Flor-Henry 1990; Roy et al. 2001). Of the major isolation effects observed here, the differential efficacy of isolation between the sexes to potentiate amphetamine-induced hyperlocomotion is in agreement with data obtained in rats (Sahakian et al. 1975). Yet, further investigations employing a higher number of subjects per group are warranted to confirm the lack of isolation effects on amphetamine-induced hyperactivity in female mice. On the other hand, the parallel between the two rodent species is less clear in terms of spontaneous locomotor activity. Similar to our observations, Abramov et al. (2004) did not find an isolation effect on spontaneous open-field activity in female C57BL6 mice; and a similar sex difference was reported in the SwissKunming hybrid mouse strain (Guo et al. 2004). These null effects in female mice are in contrast with reports in rats (Einon and Morgan 1977, 1978; Einon et al. 1981) and may indicate rooms for subtle species differences in the sexdependent effects of social isolation.

It has been suggested that the sex-dependent isolation effect reflects a general male sensitivity to environmental manipulations (Weiss et al. 2001b; Weiss and Feldon 2001). In relation to a specific behavioural model of schizophrenia - the latent inhibition model (Feldon and Weiner 1992), environmental manipulations such as early life non-handling (Peters et al. 1991; Shalev et al. 1998; Weiner et al. 1985, 1987) and prenatal stress (Shalev and Weiner 2001; Bethus et al. 2005) have been reported by several groups to disrupt latent inhibition in male but not in female rats. A similar sex difference is also reported after corticosterone administration (Shalev and Weiner 2001). These findings support the suggestion that the male sex tends to be more vulnerable to neurodevelopmental interference induced by early life environmental adversity. This is in line with the higher incidence of general developmental disturbances in the male human population (Castle et al. 1998; Seeman 1997). Although the precise biological basis of this sex difference is not known, enhanced vulnerability in the male sex may also instead (or in addition) reflect enhanced protection in the female. It has been suggested that the neuroprotective properties of estrogens may account for the lower sensitivity of females to environmental hazards (Seeman and Lang 1990; Suzuki et al. 2006). In addition to such female-specific factors, male-specific differences in brain development during the juvenile age-e.g., the greater degree of mesolimbic overproduction and subsequent pruning of dopamine receptors in males (Andersen et al. 1997; Spear 2000) may also play a crucial role in their enhanced sensitivity to social isolation.

However, there are exceptions to the 'male vulnerability' hypothesis. We have previously reported that structural changes to the home-cage in the early postweaning life that did not directly interfere with the social composition within cage resulted in more marked behavioural effects in female than in male C57BL/6 mice (Pietropaolo et al. 2007). Hence, the possibility that specific elements unique to the social isolation procedure may be critically responsible for the emergence of its sex-dependency cannot be entirely excluded. Given that social interaction amongst juvenile conspecifics plays a crucial role in the subsequent development of dominance hierarchies that is unique to male mice (Terranova et al. 1993, 1998), one may suspect that deprivation of direct social contacts exerts a more pronounced impact on the psychological development of male mice.

The psychopathological profile of the isolation syndrome: a model of schizophrenia

The present study shows that the social isolation procedure is certainly not without merits in modelling the importance of environmental factors in the genesis of schizophreniarelated psychopathology. First, the effect of social isolation on open-field activity in the male is best characterized as a delay or attenuation of locomotor habituation, given that isolated and grouped males were highly comparable in the beginning and at the end of the test period. Hence, the effect of isolation was not merely an up- or downregulation of general activity, and we did not observe a statistically significant main effect of isolation housing. The latter may be considered to be in agreement with a null effect on spontaneous locomotor activity after isolation in male C57BL/6 mice reported by Varty et al. (2006), although these authors failed to observe any change in locomotor habituation. Surprisingly, another group reported a suppressant effect of isolation on open-field activity in the same mouse strain (Dai et al. 2004, 2005), but this outcome may be unique because their test was conducted in the inactive "light" phase of the daily light-dark cycle. Indeed, it is possible that the effects of social isolation on locomotor habituation in the open field in male C57BL/6 mice are not 
robust, as they were absent in the pre-amphetamine phase of the final experiment here. Alternatively, this inconsistency might be due to the different test history of the subjects at the time of the two open-field experiments. In line with this possibility, it has been shown in rats that previous exposure to PPI testing alone was sufficient to affect the magnitude of the isolation effects on spontaneous locomotor activity in male rats (Domeney and Feldon 1998)

Here, the male isolated animals not only showed an attenuation of locomotor habituation in the open field, but also displayed a pronounced lack of startle habituation in the subsequent PPI experiment. In agreement with our interpretation, slower habituation to an open field or to objects has also been reported in isolated rats (Einon and Morgan 1976, 1978). Einon and Morgan (1978) propose that this effect stems from increased arousal to novelty. However, the lack of difference at the start of the open-field test here, when novelty was expected to be maximal, does not readily support this explanation. Alternatively, the habituation deficit may be a consequence of behavioural perseveration. Response perseveration in operant tasks (Morgan and Einon 1975), perseverative exploratory patterns (Varty et al. 2000), impaired working memory (Einon 1980), and poor reversal learning (Jones et al. 1991) have been reported in rats after social isolation. The behavioural rigidity and inflexibility in isolated animals may mimic the perseverative tendency observed in schizophrenic patients (Crider 1997; Yogev et al. 2003, 2004).

Second, we observed a clear potentiation of the amphetamine hyperlocomotor response in male mice that is in agreement with previous mouse studies (Wilmot et al. 1984, 1986). These findings in mice contrasted with the failure to obtain such an effect in Sprague-Dawley rats by Weiss et al. (2001a). As isolation also failed to enhance spontaneous locomotor activity in the same animals, these authors concluded that the two effects are inextricably linked. In the present study, we also did not observe an activity-enhancing effect of isolation in the preinjection phase of the amphetamine experiment in the male isolated mice which showed a potentiated response to amphetamine. This apparently does not support the conclusion by Weiss et al. (2001a). However, a sign of enhanced locomotor activity was detected in the male isolated mice in the form of a habituation deficit in the first open-field experiment. We therefore evaluated whether the rate of locomotor habituation in this test might predict the animals' response to amphetamine in the subsequent test. However, we failed to identify any evidence for such a link in the overall analysis including all subjects and within the amphetamine-treated isolated males. The suggestion by Weiss et al. (2001a) may therefore be applicable uniquely to rats, or even to the particular Sprague-Dawley rat strain.
Third, social isolation apparently led to sensitization of startle reactivity (instead of startle habituation) and an enhancement in startle reactivity in the male. It is likely that the former effect is partly, if not solely, responsible for the latter finding. In contrast, the opposite effect of isolation on startle reactivity in the female was not associated with any obvious changes in startle habituation. Therefore, it seems that isolation affected different psychological processes between male (sensitization/habituation) and female (startle reactivity per se), rather than it genuinely exerting opposing influences between the sexes. The apparent startle enhancement seen here in male mice resembles previous findings in both rats (Varty and Geyer 1998; Weiss et al. 1999; Wilkinson et al. 1994) and mice (Dai et al. 2005; Sakaue et al. 2003). Although Varty et al. (2006) failed to obtain a significant isolation effect on startle reactivity, a clear tendency can nonetheless be readily discerned from their data in C57BL/6 mice (see their Fig. 4, pp.165). On the other hand, our observation of startle sensitization in the same mouse strain constitutes a novel finding.

Our ability to demonstrate a sensitization effect of isolation might be facilitated by a background of weak habituation process as suggested by the performance in the male group-housed controls. According to the dual-process theory (Groves and Thompson 1970), this might have allowed an overall sensitization effect to emerge in the male isolated mice here. This view may also account for the similar pattern of results seen after perinatal isolation in rats, which led to increased startle response accompanied by a habituation failure (Finamore and Port 2000). Indeed, the lack of startle habituation has been widely described in schizophrenic patients (Geyer and Braff 1987; Geyer et al. 1990), and our results suggest that this deficit may be partly attributed to enhanced sensitization process. However, no effect of social isolation on startle habituation has been reported in rats (Varty and Geyer 1998; Weiss and Feldon 2001), and perhaps mice are preferentially affected in this respect. Comparison with previous isolation studies in mice is, however, hampered by the paucity of relevant dataonly one existing report has included analysis of startle habituation (Varty et al. 2006). Although these authors reported that startle habituation was not significantly attenuated by isolation in male $\mathrm{C} 57 \mathrm{BL} / 6$ mice, a clear tendency is revealed upon closer examination of their reported data (see their Fig. 4, pp.165) in the 6-week isolation condition. It is especially clear when one directly compares the startle reactivity in the first block with that in the last (in which only pulse-alone trials were administered), as we did here.

Fourth, there was a clear lack of an effect of isolation on PPI expression in the present study. This conclusion is based on various methods of PPI quantification, including the additional comparisons that matched the baseline 
differences in startle reactivity induced by isolation. This is the first report of a null effect of isolation in mice. It contrasts with the three existing reports of isolation-induced PPI deficit in C57BL/6 mice (Dai et al. 2004, 2005; Varty et al. 2006), all conducted in males. Common to these positive reports is that the magnitude of PPI disruption was invariably rather small, with the difference in \%PPI between isolated and grouped controls of less than $10 \%$ units. This is relatively weak in comparison to the disruption of PPI by dopaminergic agonists (amphetamine at $2.5 \mathrm{mg} / \mathrm{kg}$ i.p. and apomorphine at $2 \mathrm{mg} / \mathrm{kg} \mathrm{s.c.)} \mathrm{in} \mathrm{male}$ C57BL/6 mice, which typically ranges from $20-30 \%$ units (Yee et al. 2004), and the isolation-induced disruption reported in the rat literature (ca 30\% units reduction, e.g., in Geyer et al. 1993). Sakaue et al. (2003) reported an isolation-induced deficit of around $20 \%$ units in the DDY mouse strain, but this was accompanied by a more than twofold increase in startle reactivity. Indeed, a similar tendency of enhanced startle reactivity, albeit of a smaller magnitude and sometimes not reaching statistical significance, is also seen in C57BL/6 mice (e.g., Dai et al. 2004, 2005; Varty et al. 2006). Given that the measure of \%PPI can be substantially biased by such baseline differences, the reported reduction in \%PPI after isolation in mice might tend to be an overestimation given its already limited effect size in C57BL/6 mice amongst existing reports. Hence, the presence or absence of PPI deficit (and its severity) after isolation rearing in mice certainly warrants further evaluation, and care must be taken to account for any potential baseline startle reactivity differences. A reliance on \%PPI measure alone in such cases is indeed insufficient and at times inappropriate (Swerdlow et al. 2000; Yee et al. 2005). Resolution of this issue in mice and a similar debate over the fragility of the isolation effect on PPI in rats (Domeney and Feldon 1998; Weiss et al. 1999) will eventually decide if PPI deficiency is a central key feature of the isolation syndrome in rodents. Indeed, differences in pre-PPI testing experience may account for the discrepancies observed between our and previous studies in male C57BL/6 mice (Dai et al. 2004, 2005; Varty et al. 2006), thus suggesting that isolation-induced PPI disruption may also represent a fragile phenomenon in mice as previously demonstrated in rats (Domeney and Feldon 1998; Weiss et al. 1999).

Finally, when the overall pattern of results (in the male) is considered, the present study readily suggests that the presence of isolation effects on locomotor habituation, startle reactivity/habituation, or amphetamine response is not necessarily accompanied by a PPI deficiency. This reinforces previous suggestions that PPI deficiency, increased startle reactivity, and locomotor hyperactivity are independent (and therefore mechanistically distinct) effects of social isolation (rat:
Domeney and Feldon 1998; Geyer et al. 1993; Varty et al. 2000; mouse: Dai et al. 2004, 2005; Varty et al. 2006). Hence, the diverse features of the isolation syndrome may emerge with differing probabilities depending on various factors, such as sex, strain, species and differences in individual experience, and so they do not necessarily cooccur. This is contrary to the view that these diverse behavioural effects of social isolation essentially stem from a common brain dysfunction, namely, mesolimbic functional hyperdopaminergia (Geyer et al. 2001). A modified view with additional power of explanation posits that distinct effects of isolation rearing on locomotor activity, pulse reactivity and PPI are related to regionspecific or receptor-specific alterations in central DA functions (Geyer et al. 1993). A less parsimonious account that has received supports from several lines of research suggests that social isolation induces complex changes to a variety of neurochemical messenger systems (rat: Heidbreder et al. 2000; Jones et al. 1992; Muchimapura et al. 2002, 2003; Thoa et al. 1977; mouse: Kempf et al. 1984; Schiller et al. 2003); and perhaps the differential effects of isolation on PPI and behavioural reactivity may be accounted by the absence or presence of alterations in neurotransmitters beyond dopamine. Indeed, certain behavioural effects of social isolation may be specifically mediated by modifications of the glutamatergic system (Agis-Balboa et al. 2007; Varty and Higgins 1995), which are considered to play a crucial role in the pathogenesis of the negative and cognitive symptoms schizophrenia (Coyle and Tsai 2004; Coyle et al. 2003).

\section{Limitations of the study}

In spite of the clear demonstration of several sexdependent effects of social isolation, the interpretation of the present data needs to take into account some specific limitations of the present experimental design. First, the multiple-testing experience may reduce the magnitude of the impact of social isolation on certain behaviours here, as previously demonstrated in rats (Domeney and Feldon 1998). Hence, further investigation employing behaviourally naïve animals is warranted to confirm the lack of effects of isolation on PPI in animals of both sexes, and on amphetamine-induced hyperactivity specific to the female. Regarding the latter negative finding, replication with an increase in sample size would be particularly appropriate because the present study only had six to seven animals per group in the amphetamine experiment. It is indeed possible that the effects of isolation on the locomotor response to systemic amphetamine administration are present, but weaker in female compared to male mice, and were not detectable here because of the limited number of animals. 


\section{Conclusions}

The present study provides important qualifications and limitations to the social isolation procedure in mice as a model of schizophrenia. The preferential effect of isolation in the male sex which was observed across multiple behavioral paradigms represents the most notable positive finding. Indeed, the observed phenotypes of habituation deficit and enhanced sensitivity to psycho-stimulants do bear relevance to schizophrenia. Further investigation aiming to identify the mechanisms underlying the females' relative insensitivity to social isolation might even shed light on potential preventive interventions in high risk individuals (Compton 2004; Killackey and Yung 2007; Phillips et al. 2002).

On the other hand, we showed that PPI was not affected by social isolation in C57BL/6 mice, suggesting that postweaning social isolation alone may not be sufficient to induce robust deficiency in early attentional control. The lack of an effect on PPI - a critical endophenotype in schizophrenia (Turetsky et al. 2007) may not necessarily be a shortcoming of the model. First, PPI deficiency is not unique to schizophrenia (Perry et al. 2001, 2007). Second, this lack of an effect on PPI and the overall limited impact of social isolation on female behaviour, is in line with the expectation of one developmental perspective in the aetiology of schizophrenia, namely, the "two-hit model". In the absence of preexisting developmental disruptions (the first hit), the efficacy of environmental stressor (the second hit) to produce the full spectrum of schizophreniarelated psychopathology is expected to be limited (Maynard et al. 2001; Van den Buuse et al. 2003). Thus, social isolation rearing in $\mathrm{C} 57 \mathrm{BL} / 6$ mice may represent a valuable tool for the examination of schizophrenia-related candidate genes and their interaction with environmental stressors within the context of the "two-hit" model.

Acknowledgments The present study was supported by a Swiss National Science Foundation (SNF) 3100A0-100309/1 grant awarded to JF, with additional support by the Swiss Federal Institute of Technology, and the National Centre for Competence in Research (NCCR): Neural Plasticity and Repair. The authors also thank Peter Schmid for his technical assistance, the animal technicians for their caring of the animals, and Dr. Frank Bootz for his veterinary expertise and supervision.

\section{References}

Abramov U, Raud S, Koks S, Innos J, Kurrikoff K, Matsui T, Vasar E (2004) Targeted mutation of $\operatorname{CCK}(2)$ receptor gene antagonises behavioural changes induced by social isolation in female, but not in male mice. Behav Brain Res 155:1-11

Agis-Balboa RC, Pinna G, Pibiri F, Kadriu B, Costa E, Guidotti A (2007) Down-regulation of neurosteroid biosynthesis in cortico- limbic circuits mediates social isolation-induced behavior in mice. Proc Natl Acad Sci U S A 104:18736-18741

Andersen SL, Rutstein M, Benzo JM, Hostetter JC, Teicher MH (1997) Sex differences in dopamine receptor overproduction and elimination. Neuroreport 8:1495-1498

Angermeyer MC, Kuhn L (1988) Gender differences in age at onset of schizophrenia. An overview. Eur Arch Psychiatry Neurol Sci 237:351-364

Bakshi VP, Geyer MA (1999) Ontogeny of isolation rearinginduced deficits in sensorimotor gating in rats. Physiol Behav 67:385-392

Benton D, Brain PF (1981) Behavioral and adrenocortical reactivity in female mice following individual or group housing. Dev Psychobiol 14:101-107

Bethus I, Lemaire V, Lhomme M, Goodall G (2005) Does prenatal stress affect latent inhibition? It depends on the gender. Behav Brain Res 158:331-338

Blehar MC (1995) Gender differences in risk factors for mood and anxiety disorders: implications for clinical treatment research. Psychopharmacol Bull 31:687-691

Bradley MM, Cuthbert BN, Lang PJ (1990) Startle reflex modification: emotion or attention? Psychophysiology 27:513-522

Braff DL, Light GA, Ellwanger J, Sprock J, Swerdlow NR (2005) Female schizophrenia patients have prepulse inhibition deficits. Biol Psychiatry 57:817-820

Castle D, Sham P, Murray R (1998) Differences in distribution of ages of onset in males and females with schizophrenia. Schizophr Res 33:179-183

Cilia J, Hatcher PD, Reavill C, Jones DN (2005) Long-term evaluation of isolation-rearing induced prepulse inhibition deficits in rats: an update. Psychopharmacology (Berl) 180:57-62

Compton MT (2004) Considering schizophrenia from a prevention perspective. Am J Prev Med 26:178-185

Coyle JT, Tsai G (2004) The NMDA receptor glycine modulatory site: a therapeutic target for improving cognition and reducing negative symptoms in schizophrenia. Psychopharmacology (Berl) 174:32-38

Coyle JT, Tsai G, Goff D (2003) Converging evidence of NMDA receptor hypofunction in the pathophysiology of schizophrenia. Ann N Y Acad Sci 1003:318-327

Crider A (1997) Perseveration in schizophrenia. Schizophr Bull 23:63-74

Dai H, Okuda H, Iwabuchi K, Sakurai E, Chen Z, Kato M, Iinuma K, Yanai K (2004) Social isolation stress significantly enhanced the disruption of prepulse inhibition in mice repeatedly treated with methamphetamine. Ann N Y Acad Sci 1025:257-266

Dai H, Okuda T, Sakurai E, Kuramasu A, Kato M, Jia F, Xu AJ, Iinuma K, Sato I, Yanai K (2005) Blockage of histamine H1 receptor attenuates social isolation-induced disruption of prepulse inhibition: a study in $\mathrm{H} 1$ receptor gene knockout mice. Psychopharmacology (Berl) 183:285-293

Domeney A, Feldon J (1998) The disruption of prepulse inhibition by social isolation in the Wistar rat: how robust is the effect? Pharmacol Biochem Behav 59:883-890

Dyer DP Jr, Southwick CH (1974) A possible sensitive period for juvenile socialization in mice. Behav Biol 12:551-558

Einon D (1980) Spatial memory and response strategies in rats: age, sex and rearing differences in performance. Q J Exp Psychol 32:473-489

Einon D, Morgan MJ (1976) Habituation of object contact in sociallyreared and isolated rats (RATTUS NORVEGICUS). Anim Behav 24:415-420

Einon DF, Morgan MJ (1977) A critical period for social isolation in the rat. Dev Psychobiol 10:123-132

Einon D, Morgan MJ (1978) Habituation under different levels of stimulation in socially reared and isolated rats: a test of the arousal hypothesis. Behav Biol 22:553-558 
Einon DF, Morgan MJ, Kibbler CC (1978) Brief periods of socialization and later behavior in the rat. Dev Psychobiol $11: 213-225$

Einon DF, Humphreys AP, Chivers SM, Field S, Naylor V (1981) Isolation has permanent effects upon the behavior of the rat, but not the mouse, gerbil, or guinea pig. Dev Psychobiol 14:343-355

Ellenbroek BA, van den Kroonenberg PT, Cools AR (1998) The effects of an early stressful life event on sensorimotor gating in adult rats. Schizophr Res 30:251-260

Feldon J, Weiner I (1992) From an animal model of an attentional deficit towards new insights into the pathophysiology of schizophrenia. J Psychiatr Res 26:345-366

Finamore TL, Port RL (2000) Developmental stress disrupts habituation but spares prepulse inhibition in young rats. Physiol Behav 69:527-530

Flor-Henry P (1990) Influence of gender in schizophrenia as related to other psychopathological syndromes. Schizophr Bull 16:211-227

Fortier ME, Joober R, Luheshi GN, Boksa P (2004) Maternal exposure to bacterial endotoxin during pregnancy enhances amphetamine-induced locomotion and startle responses in adult rat offspring. J Psychiatr Res 38:335-345

Garnefski N, van Egmond M, Straatman A (1990) The influence of early and recent life stress on severity of depression. Acta Psychiatr Scand 81:295-301

Gentsch C, Lichtsteiner M, Frischknecht HR, Feer H, Siegfried B (1988) Isolation-induced locomotor hyperactivity and hypoalgesia in rats are prevented by handling and reversed by resocialization. Physiol Behav 43:13-16

George LK, Blazer DG, Hughes DC, Fowler N (1989) Social support and the outcome of major depression. Br J Psychiatry 154:478 485

Geyer MA, Braff DL (1987) Startle habituation and sensorimotor gating in schizophrenia and related animal models. Schizophr Bull 13:643-668

Geyer MA, Swerdlow NR, Mansbach RS, Braff DL (1990) Startle response models of sensorimotor gating and habituation deficits in schizophrenia. Brain Res Bull 25:485-498

Geyer MA, Wilkinson LS, Humby T, Robbins TW (1993) Isolation rearing of rats produces a deficit in prepulse inhibition of acoustic startle similar to that in schizophrenia. Biol Psychiatry 34:361-372

Geyer MA, Krebs-Thomson K, Braff DL, Swerdlow NR (2001) Pharmacological studies of prepulse inhibition models of sensorimotor gating deficits in schizophrenia: a decade in review. Psychopharmacology (Berl) 156:117-154

Goldstein JM, Seidman LJ, Makris N, Ahern T, O'Brien LM, Caviness VS Jr, Kennedy DN, Faraone SV, Tsuang MT (2007) Hypothalamic abnormalities in schizophrenia: sex effects and genetic vulnerability. Biol Psychiatry 61:935-945

Gray JA, Feldon J, Rawlins JNP, Hemsley DR, Smith AD (1991) The neuropsychology of schizophrenia. Behav Brain Res 14:1-84

Groves PM, Thompson RF (1970) Habituation: a dual-process theory. Psychol Rev 77:419-450

Guidotti A, Dong E, Matsumoto K, Pinna G, Rasmusson AM, Costa E (2001) The socially-isolated mouse: a model to study the putative role of allopregnanolone and 5alpha-dihydroprogesterone in psychiatric disorders. Brain Res Brain Res Rev 37:110-115

Guo M, Wu CF, Liu W, Yang JY, Chen D (2004) Sex difference in psychological behavior changes induced by long-term social isolation in mice. Prog Neuropsychopharmacol Biol Psychiatry 28:115-1121

Hanna EZ, Grant BF (1997) Gender differences in DSM-IV alcohol use disorders and major depression as distributed in the general population: clinical implications. Compr Psychiatry 38:202-212

Harrison PJ (1997) Schizophrenia: a disorder of neurodevelopment? Curr Opin Neurobiol 7:285-289
Hatch AM, Wiberg GS, Zawidzka Z, Cann M, Airth JM, Grice HC (1965) Isolation syndrome in the rat. Toxicol Appl Pharmacol 7:737-745

Hauser J, Feldon J, Pryce CR (2006) Prenatal dexamethasone exposure, postnatal development, and adulthood prepulse inhibition and latent inhibition in Wistar rats. Behav Brain Res 175:5161

Heidbreder CA, Weiss IC, Domeney AM, Pryce C, Homberg J, Hedou G, Feldon J, Moran MC, Nelson P (2000) Behavioral, neurochemical and endocrinological characterization of the early social isolation syndrome. Neuroscience 100:749-768

Jones GH, Marsden CA, Robbins TW (1990) Increased sensitivity to amphetamine and reward-related stimuli following social isolation in rats: possible disruption of dopamine-dependent mechanisms of the nucleus accumbens. Psychopharmacology (Berl) 102:364-372

Jones GH, Marsden CA, Robbins TW (1991) Behavioural rigidity and rule-learning deficits following isolation-rearing in the rat: neurochemical correlates. Behav Brain Res 43:35-50

Jones GH, Hernandez TD, Kendall DA, Marsden CA, Robbins TW (1992) Dopaminergic and serotonergic function following isolation rearing in rats: study of behavioural responses and postmortem and in vivo neurochemistry. Pharmacol Biochem Behav 43:17-35

Kempf E, Puglisi-Allegra S, Cabib S, Schleef C, Mandel P (1984) Serotonin levels and turnover in different brain areas of isolated aggressive or non-aggressive strains of mice. Prog Neuropsychopharmacol Biol Psychiatry 8:365-371

Killackey E, Yung AR (2007) Effectiveness of early intervention in psychosis. Curr Opin Psychiatry 20:121-125

Koch M, Schnitzler HU (1997) The acoustic startle response in ratscircuits mediating evocation, inhibition and potentiation. Behav Brain Res 89:35-49

Krebs-Thomson K, Giracello D, Solis A, Geyer MA (2001) Postweaning handling attenuates isolation-rearing induced disruptions of prepulse inhibition in rats. Behav Brain Res 120:221-224

Kumari V, Aasen I, Sharma T (2004) Sex differences in prepulse inhibition deficits in chronic schizophrenia. Schizophr Res 69:219-235

Lapiz MD, Mateo Y, Durkin S, Parker T, Marsden CA (2001) Effects of central noradrenaline depletion by the selective neurotoxin DSP-4 on the behaviour of the isolated rat in the elevated plus maze and water maze. Psychopharmacology (Berl) 155:251-259

Laruelle M, Abi-Dargham A, Gil R, Kegeles L, Innis R (1999) Increased dopamine transmission in schizophrenia: relationship to illness phases. Biol Psychiatry 46:56-72

Lehmann J, Feldon J (2000) Long-term biobehavioral effects of maternal separation in the rat: consistent or confusing? Rev Neurosci 11:383-408

Leng A, Feldon J, Ferger B (2004) Long-term social isolation and medial prefrontal cortex: dopaminergic and cholinergic neurotransmission. Pharmacol Biochem Behav 77:371-379

Maisonnette S, Morato S, Brandao ML (1993) Role of resocialization and of 5-HT1A receptor activation on the anxiogenic effects induced by isolation in the elevated plus-maze test. Physiol Behav 54:753-758

Maynard TM, Sikich L, Lieberman JA, LaMantia AS (2001) Neural development, cell-cell signaling, and the "two-hit" hypothesis of schizophrenia. Schizophr Bull 27:457-476

Meyer U, Feldon J, Schedlowski M, Yee BK (2005) Towards an immuno-precipitated neurodevelopmental animal model of schizophrenia. Neurosci Biobehav Rev 29:913-947

Moragrega I, Carrasco MC, Vicens P, Redolat R (2003) Spatial learning in male mice with different levels of aggressiveness: 
effects of housing conditions and nicotine administration. Behav Brain Res 147:1-8

Morgan M, Einon D (1975) Incentive motivation and behavioral inhibition in socially-isolated rats. Physiol Behav 15:405-409

Muchimapura S, Fulford AJ, Mason R, Marsden CA (2002) Isolation rearing in the rat disrupts the hippocampal response to stress. Neuroscience 112:697-705

Muchimapura S, Mason R, Marsden CA (2003) Effect of isolation rearing on pre- and post-synaptic serotonergic function in the rat dorsal hippocampus. Synapse 47:209-217

Pellow S, File SE (1986) Anxiolytic and anxiogenic drug effects on exploratory activity in an elevated plus-maze: a novel test of anxiety in the rat. Pharmacol Biochem Behav 24:525-529

Perry W, Minassian A, Feifel D, Braff DL (2001) Sensorimotor gating deficits in bipolar disorder patients with acute psychotic mania. Biol Psychiatry 50:418-424

Perry W, Minassian A, Lopez B, Maron L, Lincoln A (2007) Sensorimotor gating deficits in adults with autism. Biol Psychiatry 61:482-486

Peters SL, Gray JA, Joseph MH (1991) Pre-weaning non-handling of rats disrupts latent inhibition in males, and results in persisting sex- and area-dependent increases in dopamine and serotonin turnover. Behav Pharmacol 2:215-223

Phillips LJ, Yung AR, Yuen HP, Pantelis C, McGorry PD (2002) Prediction and prevention of transition to psychosis in young people at incipient risk for schizophrenia. Am J Med Genet 114:929-937

Pietropaolo S, Branchi I, Cirulli F, Chiarotti F, Aloe L, Alleva E (2004) Long-term effects of the periadolescent environment on exploratory activity and aggressive behaviour in mice: social versus physical enrichment. Physiol Behav 81:443-453

Pietropaolo S, Feldon J, Alleva E, Cirulli F, Yee BK (2006) The role of voluntary exercise in enriched rearing: a behavioral analysis. Behav Neurosci 120:787-803

Pietropaolo S, Mintz M, Feldon J, Yee BK (2007) The behavioral sequela following the prevention of home-cage grid-climbing activity in C57BL/6 mice. Behav Neurosci 121:345-355

Pietropaolo S, Feldon J, Yee BK (2008) Non-physical contact between cage-mates alleviates the social isolation syndrome in male C57B1/6 mice. Behav Neurosci (in press)

Prut L, Belzung C (2003) The open field as a paradigm to measure the effects of drugs on anxiety-like behaviors: a review. Eur J Pharmacol 463:3-33

Pryce CR, Bettschen D, Bahr NI, Feldon J (2001) Comparison of the effects of infant handling, isolation, and nonhandling on acoustic startle, prepulse inhibition, locomotion, and HPA activity in the adult rat. Behav Neurosci 115:71-83

Raedler TJ, Schreiner A, Naber D, Wiedemann K (2006) Genderspecific effects in the treatment of acute schizophrenia with risperidone. Pharmacopsychiatry 39:171-174

Renner MJ, Rosenzweig MR (1987) Enriched and impoverished environments. Springer, Berlin Heidelberg New York

Roy MA, Maziade M, Labbe A, Merette C (2001) Male gender is associated with deficit schizophrenia: a meta-analysis. Schizophr Res 47:141-147

Ruedi-Bettschen D, Pedersen EM, Feldon J, Pryce CR (2005) Early deprivation under specific conditions leads to reduced interest in reward in adulthood in Wistar rats. Behav Brain Res 156:297-310

Sahakian BJ, Robbins TW, Morgan MJ, Iversen SD (1975) The effects of psychomotor stimulants on stereotypy and locomotor activity in socially-deprived and control rats. Brain Res 84: 195-205

Sakaue M, Ago Y, Baba A, Matsuda T (2003) The 5-HT1A receptor agonist MKC-242 reverses isolation rearing-induced deficits of prepulse inhibition in mice. Psychopharmacology (Berl) 170:7379
Schiller L, Jahkel M, Kretzschmar M, Brust P, Oehler J (2003) Autoradiographic analyses of 5-HT1A and 5-HT2A receptors after social isolation in mice. Brain Res 980:169-178

Seedat S, Fritelli V, Oosthuizen P, Emsley RA, Stein DJ (2007) Measuring anxiety in patients with schizophrenia. J Nerv Ment Dis 195:320-324

Seeman MV (1997) Psychopathology in women and men: focus on female hormones. Am J Psychiatry 154:1641-1647

Seeman MV, Lang M (1990) The role of estrogens in schizophrenia gender differences. Schizophr Bull 16:185-194

Shalev U, Weiner I (2001) Gender-dependent differences in latent inhibition following prenatal stress and corticosterone administration. Behav Brain Res 126:57-63

Shalev U, Feldon J, Weiner I (1998) Gender- and age-dependent differences in latent inhibition following pre-weaning nonhandling: implications for a neurodevelopmental animal model of schizophrenia. Int J Dev Neurosci 16:279-288

Smith JK, Neill JC, Costall B (1997) Post-weaning housing conditions influence the behavioural effects of cocaine and d-amphetamine. Psychopharmacology (Berl) 131:23-33

Spear LP (2000) The adolescent brain and age-related behavioral manifestations. Neurosci Biobehav Rev 24:417-463

Suzuki S, Brown CM, Wise PM (2006) Mechanisms of neuroprotection by estrogen. Endocrine 29:209-215

Swerdlow NR, Braff DL, Geyer MA (2000) Animal models of deficient sensorimotor gating: what we know, what we think we know, and what we hope to know soon. Behav Pharmacol 11:185-204

Terranova ML, Laviola G, Alleva E (1993) Ontogeny of amicable social behavior in the mouse: gender differences and ongoing isolation outcomes. Dev Psychobiol 26:467-481

Terranova ML, Laviola G, de Acetis L, Alleva E (1998) A description of the ontogeny of mouse agonistic behavior. J Comp Psychol $112: 3-12$

Thoa NB, Tizabi Y, Jacobowitz DM (1977) The effect of isolation on catecholamine concentration and turnover in discrete areas of the rat brain. Brain Res 131:259-269

Turetsky BI, Calkins ME, Light GA, Olincy A, Radant AD, Swerdlow NR (2007) Neurophysiological endophenotypes of schizophrenia: the viability of selected candidate measures. Schizophr Bull 33:69-94

Valzelli L (1973) The "isolation syndrome" in mice. Psychopharmacologia 31:305-320

Van den Buuse M, Garner B, Koch M (2003) Neurodevelopmental animal models of schizophrenia: effects on prepulse inhibition. Curr Mol Med 3:459-471

Varty GB, Geyer MA (1998) Effects of isolation rearing on startle reactivity, habituation, and prepulse inhibition in male Lewis, Sprague-Dawley, and Fischer F344 rats. Behav Neurosci $112: 1450-1457$

Varty GB, Higgins GA (1995) Examination of drug-induced and isolation-induced disruptions of prepulse inhibition as models to screen antipsychotic drugs. Psychopharmacology (Berl) 122:15-26

Varty GB, Braff DL, Geyer MA (1999) Is there a critical developmental 'window' for isolation rearing-induced changes in prepulse inhibition of the acoustic startle response? Behav Brain Res 100:177-183

Varty GB, Paulus MP, Braff DL, Geyer MA (2000) Environmental enrichment and isolation rearing in the rat: effects on locomotor behavior and startle response plasticity. Biol Psychiatry 47:864-873

Varty GB, Powell SB, Lehmann-Masten V, Buell MR, Geyer MA (2006) Isolation rearing of mice induces deficits in prepulse inhibition of the startle response. Behav Brain Res 169:162-167

Weiner I, Schnabel I, Lubow RE, Feldon J (1985) The effects of early handling on latent inhibition in male and female rats. Dev Psychobiol 18:291-297 
Weiner I, Feldon J, Ziv-Harris D (1987) Early handling and latent inhibition in the conditioned suppression paradigm. Dev Psychobiol 20:233-240

Weiss IC, Feldon J (2001) Environmental animal models for sensorimotor gating deficiencies in schizophrenia: a review. Psychopharmacology (Berl) 156:305-326

Weiss IC, Feldon J, Domeney AM (1999) Isolation rearing-induced disruption of prepulse inhibition: further evidence for fragility of the response. Behav Pharmacol 10:139-149

Weiss IC, Di Iorio L, Feldon J, Domeney AM (2000) Strain differences in the isolation-induced effects on prepulse inhibition of the acoustic startle response and on locomotor activity. Behav Neurosci 114:364-373

Weiss IC, Domeney AM, Heidbreder CA, Moreau JL, Feldon J (2001a) Early social isolation, but not maternal separation, affects behavioral sensitization to amphetamine in male and female adult rats. Pharmacol Biochem Behav 70:397-409

Weiss IC, Domeney AM, Moreau JL, Russig H, Feldon J (2001b) Dissociation between the effects of pre-weaning and/or postweaning social isolation on prepulse inhibition and latent inhibition in adult Sprague-Dawley rats. Behav Brain Res 121:207-218

Weiss IC, Pryce CR, Jongen-Relo AL, Nanz-Bahr NI, Feldon J (2004) Effect of social isolation on stress-related behavioural and neuroendocrine state in the rat. Behav Brain Res 152:279-295

Wilkinson LS, Killcross SS, Humby T, Hall FS, Geyer MA, Robbins TW (1994) Social isolation in the rat produces developmentally specific deficits in prepulse inhibition of the acoustic startle response without disrupting latent inhibition. Neuropsychopharmacology 10:61-72

Wilmot CA, Vander Wende C, Spoerlein MT (1984) Behavioral responses to apomorphine and amphetamine in differentially housed mice. Psychopharmacology (Berl) 84:105-108

Wilmot CA, VanderWende C, Spoerlein MT (1986) Behavioral and biochemical studies of dopamine receptor sensitivity in differentially housed mice. Psychopharmacology (Berl) 89:364-369

Wright IK, Ismail H, Upton N, Marsden CA (1991) Effect of isolation rearing on 5-HT agonist-induced responses in the rat. Psychopharmacology (Berl) 105:259-263

Yee BK, Russig H, Feldon J (2004) Apomorphine-induced prepulse inhibition disruption is associated with a paradoxical enhancement of prepulse stimulus reactivity. Neuropsychopharmacology 29:240-248

Yee BK, Chang T, Pietropaolo S, Feldon J (2005) The expression of prepulse inhibition of the acoustic startle reflex as a function of three pulse stimulus intensities, three prepulse stimulus intensities, and three levels of startle responsiveness in C57BL6/J mice. Behav Brain Res 163:265-276

Yogev H, Hadar U, Gutman Y, Sirota P (2003) Perseveration and over-switching in schizophrenia. Schizophr Res 61:315-321

Yogev H, Sirota P, Gutman Y, Hadar U (2004) Latent inhibition and overswitching in schizophrenia. Schizophr Bull 30:713-726

Zorrilla EP (1997) Multiparous species present problems (and possibilities) to developmentalists. Dev Psychobiol 30:141150 